\title{
Research on Project Driven and Modified Traditional Teaching Mode based Novel Oracle Database Teaching Methodology and Reform
}

\author{
Yan Zhang ${ }^{1}$ \\ ${ }^{1}$ Department of Computer Science, \\ Changsha Medical University, \\ Changsha 410219, Hunan, China
}

\author{
Cong Wang ${ }^{2}$ \\ ${ }^{2}$ Hunan Institute of Information Technology, \\ Changsha City, Hunan Province, P.R.China, \\ 410151
}

\author{
Jian-Ming $\mathrm{Li}^{3,4,{ }^{*}}$ \\ ${ }^{3}$ Neuroscience Research Center, \\ Changsha Medical University, \\ Changsha 410219, Hunan, China \\ ${ }^{4}$ Department of Anatomy and Neurobiology, \\ Central South University Xiangya School of Medicine, \\ Changsha 410013, Hunan, China \\ corresponding author
}

\begin{abstract}
In this paper, we research on the project driven and modified traditional teaching mode based novel oracle database teaching methodology and reform. As the main foundation of computer application system and information system and core technology, the database is the most rapid development of computer science and technology and the application in a wide range of fields. The Oracle database is a useful and practical computer science and technology. Combining project methodology will enhance the performance of the education which will be meaningful. In the near future, we plan to research more on the characteristics of the Oracle teaching.
\end{abstract}

Keywords: Oracle Database; Education Reform; Project Driven; Performance Evaluation.

\section{Introduction}

With the development of computer technology, computer application system development more and more which need a large number of professional and technical personnel to master large relational databases, train and bring up the professional staff has become the demand of the times which is a very important aspect in the university computer teaching. Due to the large database in an important status and role in computer application system development, to concentrate on teaching of large relational databases have no other choice. At the same time, the large relational database is a practical course, students are learning after the database basic theory, through the study of the large relational database and it can deepen the understanding of the theory of database, improve and develop the integrated use of knowledge and ability to solve practical problems. To the students' scientific research ability, engineering ability and innovation ability training plays an important role. As the main foundation of computer application system and information system and core technology, the database is the most rapid development of computer science and technology and the application in a wide range of fields. The Oracle database is a useful and practical computer science and technology. Through the study of the Oracle database, students can master the basic theory of Oracle database concepts, SQL programming techniques, and language, learn to configure and install the relevant database software which will improve the ability of maintenance and management database [1]. 
In the teaching of the traditional database, Oracle database content too much most of the students reaction and it is difficult to grasp. Because in the teaching of the past is pay attention to the database the transmission of knowledge and are to be carried out according to the written order of the teaching material of teaching, sometimes on the arrangement of the content of the chapters. So, the students learn more difficult. If we want to training excellent talent with strong social adaptation ability, we must reform the existing teaching methods. As a kind of heuristic teaching method, the behavior of the project teaching method is through leadership, organize students to participate in design projects, and complete the teaching mission in the process of implementation of the project of a kind of teaching method. The teaching aim of project teaching method is the enterprise of professional behavior and pays attention to students' comprehensive ability and the comprehensive training of comprehensive quality. The project teaching method is mainly refers to the theory of knowledge in the process of teaching the specific project as the teaching goal, the teaching as the main line of the project. The knowledge related to the Oracle database slowly into all aspects of project teaching, and then in the propulsion project step by step, and then complete the implementation and design of the whole project [2-5]. Through step by step to complete the project, the theoretical knowledge into practical and intuitive content to further improve the students' learning initiative and interest in learning process.

To deal with the mentioned challenges, we research on the project driven and modified traditional teaching mode based novel oracle database teaching methodology and reform in this paper. At present, the technology of the Oracle database is an important course of computer related major education in colleges and universities and its architecture principle as the core of the course content, design, development, management, optimization which is necessary to know. At present, some teaching materials in this paper introduces the principle, system structure is mainly to explain the role of each part, not through the application of the specific case to explain in detail the principle and the students learning boring, the feeling is very deep and difficult to understand and so cannot be lift students' interest in learning Oracle database. Therefore, combining the project design steps with teaching will be effective and necessary. The project chosen in this paper is the optimization of the database structure which is visually shown in the figure one. 


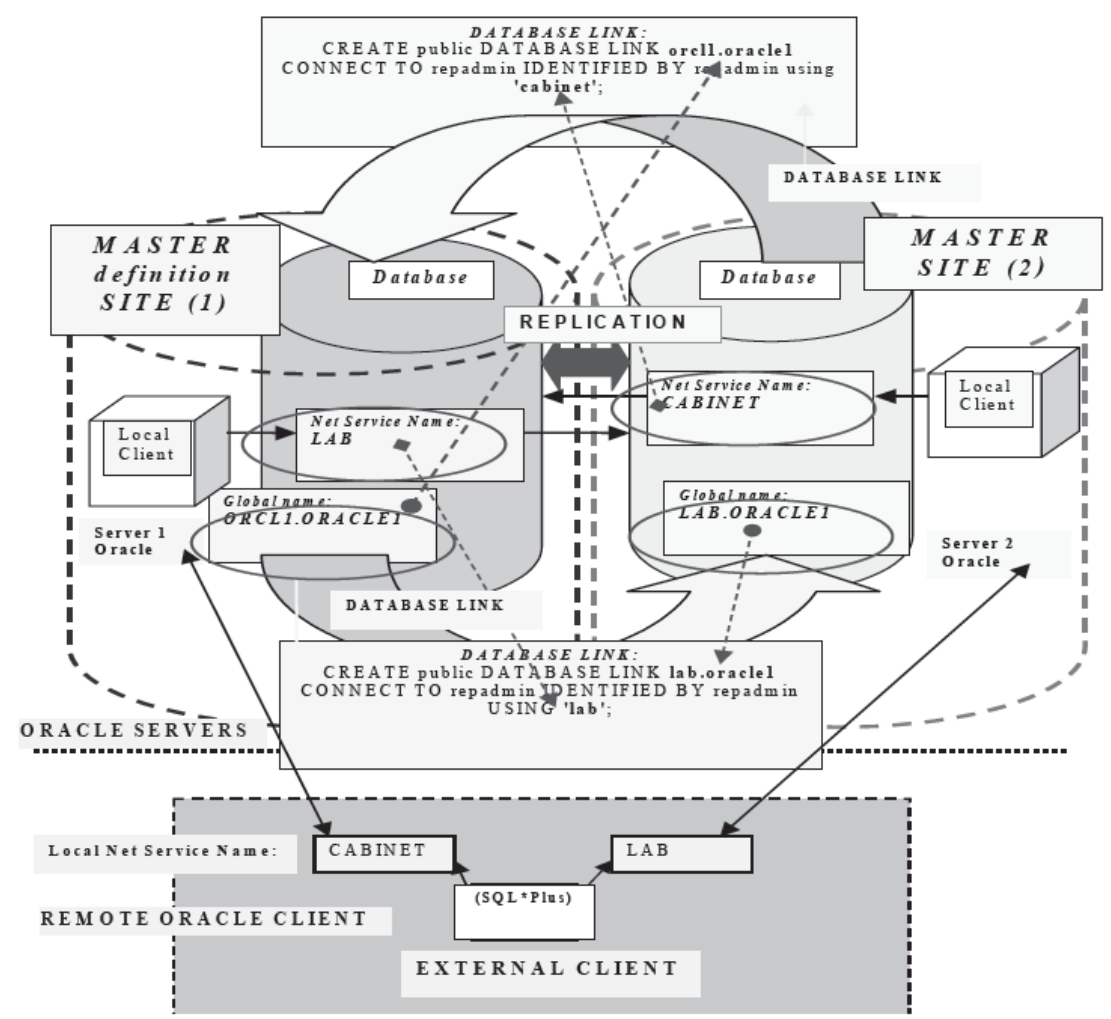

Fig. 1The Project Structure used for Analyzing in the Paper

\section{The Proposed Methodology}

\section{The Concepts of Traditional Oracle Database}

Education. At present, the Oracle database system is one of the world's most popular large relational database system and the powerful data storage and management ability which holds good scalability and availability, high safety and reliability. In distributed database systems, data stored in a logically unified but geographically distributed in different location of the database, the database can be remote access via the Internet. Distribution at different locations due to database, data access and management become very complicated. With a large number of the adoption of multimedia teaching way, Oracle also has a lot of multimedia network teaching resources. In the organization and design teaching plans can make full use of these resources to enrich the teaching content, but will speed up the rhythm of the classroom demonstration, multimedia teaching has caused many students is difficult to keep up with the progress of curriculum, directly affect the students' understanding of teaching knowledge and the quality of teaching. Due to the Oracle database content distracting and large architecture, a lot of professional terms and concepts are abstract, so directly understand the content is very difficult for many students. And because a lot of school teaching conditions, teaching pay attention to more is the theory content of Oracle database, specific database operation process, lets the student participate in very few, even many interactive example demonstrates the operation of the process is just using the PPT show, causing students seldom come into contact with the link to solve practical problems to give students perceptual knowledge is not strong. Therefore, the current teaching pattern should be modified.

The Principle of Project Driven and Modified Traditional Teaching Mode. Oracle database is the applied and practical technology specialty, combined with years of experience in 
teaching, deeply on the theory and practice of teaching this course should break through the inherent teaching mode to reform it. In this paper, by adopting the idea of the project teaching method as well as applications of the course teaching reform we finalize the process of modification. First through carefully set question to answer students to learn the knowledge of the reason, you need the teacher to let students know the knowledge of the substance and finally let the students know the knowledge will be used in what place, can even show briefly how to use, to lay the foundation for practice lesson. And project teaching method, heuristic teaching form is a kind of behavior is really by organizing students to participate in project design, fully complete the teaching mission in the process of project implementation process and it is a modern enterprise of professional behavior as the goal, it emphasizes the students' comprehensive ability as a kind of teaching way of comprehensive training.

A striking feature of this course is to learn and master the theoretical knowledge and more complex, so this article puts forward project teaching method as the auxiliary teaching means to understand the basic concepts and theories of should try to downplay theory study at the same time and to overcome the abstract from the actual state of passive learning, prevent students from pure phenomenon of the concept of speakers. Teaching means not only to the use of advanced multimedia teaching methods in teaching, but also pay attention to the combination of multimedia and blackboard writing, so as to overcome the disadvantages of multimedia in the teaching, and according to the particularity of the course, should increase the appropriate demo link, you can take the video playback, field demonstrates a variety of ways, such as built environment, makes the course from the traditional teaching mode of rigid, more affectionately, increase students' interest in learning.
The Project based Teaching Methodology. It is mainly used in the practice teaching mode "project teaching method" by teachers to choose a suitable small practice project which let the students in the completion of the project guide next step by step, gradually to the Oracle database to manage and maintain the basic operation of the master, this is a new teaching mode. Specific can take the student as the main body, grouping, in the form of group to complete the project planning and decision making. In the process, not only cultivate the students' ability of self-study, also strengthened their cooperation consciousness. We choose the Oracle database multi-master replication as the project to teach. The structure of Oracle could be separated into the following sections. Learning project instance allows students to understand and to use Oracle faster related knowledge and technology. In the course of time, to the Oracle database management information system to the student presentation for the background, and show the important role played by the Oracle database in the system. In the later each hall theory class teaching process, are available from the management information system to extract the corresponding modules as the teaching examples, corresponding to the knowledge teaching, demonstrates its implementation in the system, can make students more image understanding, deepen our memory. The following code block is the demonstration.

$\mathrm{C}:$ | > sqlplus scott/tiger

SQL>drop table t_object;

SQL>create table t_object as select * from all_objects;

SQL>create index idx_object on t_object(object_id);

SQL>set autotrace on;

SQL>set linesize 1000;

SQL> set timing on;

SQL> select object_name from t_object where object_id $=4$;

SQL> select object_name from t_object where object_id=4; 
In practice, we attempt to ORACLE in the content of the course, we have a student achievement management system, for example, starting from the system demand analysis, introduces the entity relationship physical structure design, system logic structure design, system design, database design, implementation and system storage process triggers initialization, data export and design. It should be pointed out that, as a result of the field key encryption using asymmetric encryption algorithm, so the safety of the field key management problem is converted to how to guarantee the security of authorized user private key, this means that the user's private key is bound to in the form of a cipher text stored in the encrypted in the dictionary. In the example in the whole process of system development lets the student understand the application of database technology in the project development and to master the knowledge used in practice.

The Prospect and Pattern Optimization. Large relational database teaching put forward higher request to teachers and students, need in teaching practice and exploration, instant summary, continuous improvement, in order to make clear the training target to choose the teaching content, to specific practical application for the teaching guide, focusing on the real system development design practice, will be able to get good teaching effect in the teaching practice, improve the level of theory and practice of students, cultivate the students' professional quality. As long as we sincerely for the students' benefit, for the social service, we will be able to make the job of teaching of university education is popular among the students, are recognized by the society, and constantly improve the level of our school, for the country to cultivate more and better useful talents for the society, the service construction of socialist harmonious society and promote the great rejuvenation of the Chinese nation. Teachers in the process of lecture to adopt new methods of education should not just like a traditional education method to let the students mechanical to listen to the teacher. The teacher wants to ask the student questions in the process of lecture to the students themselves to think and to encourage the students took to the podium to explain their own ideas. This way will not only exercise the students' language ability of organization but also help the students form in our subjective initiative to adapt to the Oracle database the thinking mode of learning.

\section{Conclusion}

With the continuous development of database theory, Oracle has been an important method to deal with data processing tasks. In this paper, we research on the project driven and modified traditional teaching mode based novel oracle database teaching methodology and reform. In the teaching of the traditional database, Oracle database content too much most of the students reaction and it is difficult to grasp. Because in the teaching of the past is pay attention to the database the transmission of knowledge and are to be carried out according to the written order of the teaching material of teaching. The project driven will enhance the practical experience for students which will be necessary. In the future, we plan to conduct more literature review to modify the current methodology.

\section{Acknowledgement}

We sincerely appreciate the careful and professi onal review of the referees as well as the valuabl e comments for the improvement of the paper.

This work has been supported by the Scientific Research Fund of Education Depa rtment of Hunan Province (Grant Nos. 12C0505 ,14C0112, 14B024 and 14C0126), Hunan Province Education Science "Twelfth-Fi ve Year Plan" project of China (Grant No. XJK0 13CGD104 and XJK013BGD014) and Hunan province education reform project of Chi na (Grant No. [2013]223-510). 


\section{References}

[1] Xiang-rong, H. (2014). Optimization techniques discussed in oracle database integration process. Computer Programming Skills \& Maintenance.

[2] Yao, S. C. (2014). Research on performance optimization scheme of oracle database. Applied Mechanics \& Materials, 687-691.

[3] Feng, W. (2014). Application of oracle database optimization techniques in production management information system of railway freight station. Railway Computer Application.

[4] Ling, Z., Qi, L., Qianyuan, Z., \& Wei, C. (2013). The study of adjustment and optimization of oracle database in information system. Fourth International Conference on Computational \& Information Sciences (pp.442-445).

[5] Ying, Y. (2013). Oracle performance tuning and optimization analysis. Information Security Technology. 